\title{
OUDE VERDICHTE VERHALEN OVER GUIANA
}

Eenigen tijd geleden verraste mij een onzer letterkundigen met de mededeeling, dat hij een boek op het spoor was gekomen, handelende in Suriname ${ }^{1}$ ), dat niet genoemd is in het artikel „,romans, dichtwerken, enz." in de Encyclopaedie van Nederlandsche West-Indie"'. Tevens vestigde hij mijne aandacht op de studie „Elisabeth Maria Post" van J. Koopmans in "De Berweging" van Juli en Augustus 1914. Ik verwees hem naar het woord van Plato dat als motto staat boven het voorwoord dier Encyclopaedie: „Wel is het de taak van een goed jager om het wild op te sporen in een groot bosch; maar men kan het hem niet aanwrijven indien hij niet alles schiet."

$\mathrm{Nu}$,aanwrijven" heeft zeker allerminst in de bedoeling gelegen.

Het wild moest nu opgespoord, wat na eenig zoeken gelukte. Achteraf bleek het boek niet zoo heel zeldzaam te zijn. Inmiddels las ik de voortreffelijke studie van Koopmans, waarin een uitvoerige beschouwing van „Reinhart of Natuur en Godsdienst" wordt gegeven en men de schrijfster ziet in de lijst van haar tijd.

Het is niet mijn doel het boek als letterkundig voortbrengsel te bespreken, waartoe ik mij niet bevoegd acht en wat ook geheel overbodig zou zijn na de studie van Koopmans. Ik wil er slechts de aandacht op vestigen van hen die belang stellen in de litteratuur over Guiana en mij voorts eenige opmerkingen veroorloven. En dan begin ik met eerlijk te bekennen dat ik al mijn wilskracht noodig had om de drie deelen, tezamen 1069 bladzijden, door te komen. Men moet meer letterkundigen aanleg bezitten

1) Elisabeth Maria Post. Reinhart of Natuur en Godsdienst. Drie deelen met platen en portret van de schrijfster. Amsterdam, Johannes Allart, $1791-92$. 
dan waarover ik beschik, om zulke geschriften te waardeeren.

Reinhart is - aldus Koopmans - ,het om en nabije beeld van een eigen broer, die naar de West getrokken is, om er zijn fortuin te zoeken, en - mogelik - van daar uit zijne familie te kunnen steunen, of wel na zijn terugkomst in staat te kunnen zijn, oude eereschulden af te doen."

„In Guyana - leest men verder bij Koopmans - gaat het de nieuwe kolonist voor de wind. Hij begint met opzichter te worden op een groot landgoed, ,,en als hij op zekeren dag met een opdracht naar een naburige plantage wordt gezonden, ontmoet hij daar als eigenaar een simpathiek persoon, die eveneens zich onmiddellijk tot Reinhart voelt aangetrokken. En ziedaar, de planter van $L a$ bonne Espérance vindt in de jongeling de zoon van een vroeger vriend in 't moederland terug. Als nu Reinhart het lot van zijn vader, de moeilike omstandigheden waarin zijn familie verkeert en de reden, die hem naar Amerika heeft gedreven, aan de belangstellend luisterende Edelhart heeft meegedeeld, is diens besluit genomen. Enige dagen later krijgt Reinhart, die inmiddels zijn gewone werkzaamheden op het landgoed van zijn meester heeft opgevat, van zijn vaderlike vriend een schrijven, waarin deze hem de heugelike tijding doet geworden, dat hij door aankoop de eigenaar is geworden van een drie uren verder gelegen plantage, waarvan de eigenaar is gestorven en het onderhoud schromelijk is verwaarloosd, maar die, aangezien het terrein zich uitstekend voor allerlei kultuur leent, bij noeste arbeid een rijke bron van inkomsten kan worden. Deze gronden biedt hij de brave zoon van een beminde vriend als een bewijs van achting aan. Twaalf slaven zijn bij die edelmoedige schenking inbegrepen, en reeds aan 't werk gezet. Reinhart is overgelukkig. Hij komt, en ziet, en overwint met een hoopvol vertrouwen en een verlevendigde moed alle moeielikheden. De ingestorte woningen worden herbouwd, de overwoekerde gronden ontgonnen en bezaaid; het slavental op veertig gebracht, en hoe langer hoe meer in kultuur gebrachte tuinen aan de suikerteelt, de katoenbouw en de koffiepluk toegewezen. Eerst behelpt hij zich in een schuur; als de werkzaamheden het toelaten sticht hij zich een geriefeliker woning". ....

Aan zijn plantage - vanwaar de brieven geschreven zijn, waaruit het boek bestaat - geeft hij den naam "L'Heureuse Solitude".

Reinhart vindt in Guiana een vrouw naar zijn hart - 
dedochter van een naburigen planter, Dubingthon geheeten - wordt vader van twee lieve kinderen, verliest na eenige jaren van gelukkig samenleven zijn vrouw en verlaat daarop het land.

Wat mij er toe gebracht heeft het boek door te lezen zijn de volgende woorden van Koopmans:

„Zij, die langs de hiergespannen draad, de hoofdstukken van dit langgerekte boek volgen, staan verrukt over de natuur beschrijvingen op de oceaan, en in de tropische wereld. Ook die, welke land- en volkenkundig bedoeld zijn, en hierom reeds van 't hoogste belang zijn en ook steeds belangwekkend zullen blijven, zijn elegies omfloerst of idyllies-geglansd. Een tiental er van, op boom- en bladvliezen geschreven, schetsen het verre Indianen gebied".

Ik wenschte te weten wat het boek op land- en volkenkundig gebied zou geven en hoopte er ook het een en ander in te vinden omtrent het maatschappelijk leven in die dagen. Hierin nu ben ik te leur gesteld. De anders zoo uitvoerige briefschrijver zwijgt daarover, met een enkele uitzondering, waarop ik hier onder terug kom.

Een weldadig aandoende liefde voor de natuur straalt door het heele boek. De beschrijvingen van planten en dieren zijn treffend mooi en doorgaans juist, maar de terreinbeschrijvingen berusten op fantasie en passen niet op het kustgebied van Suriname of de andere toenmaals Nederlandsche Koloniën in Guiana, en L'Heureuse Solitude lag, volgens mededeelingen op verscheidene plaatsen in het boek niet ver van zee. De schrijfster mag men daarvan geen verwijt maken. $\mathrm{Zij}$ toch verklaart in de opdracht aan haren broeder, dat het boek zijn aanwezen aan hem verschuldigd is, schoon het noch zijn lot, noch zijn persoon, noch bepaald zijn verblijf afteekent, en in het woord tot haar ,geëerde Landgenooten" gericht verzekert ze nog eens dat het boek een schepsel harer verbeeldinge is , die zig meestal door de waarheid liet leiden”. Ik meen dit laatste zoo te moeten opvatten dat zij steunde op de brieven van haar broeder, maar overigens aan haar fantasie den vrijen loop liet. Dat de levensloop van haar broeder geenszins die is van Reinhart blijkt trouwens uit 
verscheidene van haar andere geschriften, zoo b.v. uit den bundel „Voor Eenzamen”.

Trots deze wetenschap kon ik de verzoeking niet weerstaan uit te vorschen waar in Guiana Reinhart, of liever de broeder, gewoond heeft en wanneer. In het boek nergens een jaartal behalve dan het jaar van uitgave, 1791 . Koopmans spreekt van „de West” en „Guyana”, maar in een in 1913 te Epe verschenen gelegenheidsgeschrift „Elisabeth Maria Post I755-I8I2. Haar leven en geschriften", door H. W. Heuvel. Met voorwoord en aanteekeningen van Ds. J. A. Prins, wordt Suriname genoemd als de kolonie waarheen de broeder was getrokken.

In het betreffende artikel vermeldt het „Biographisch Woordenboek" onder de werken van mejuffrouw Post: „Ter nagedachtenis van mijnen waardigen broeder $H$. $H$. Post", waarbij de schrijver van het artikel (Van Schevikhaven) opmerkt: „in 1809 te Demerari overleden (bovengenoemde Reinhart)". Het is mij niet gelukt dit geschrift van mej. Post op te sporen. De dames Dusseau te Amsterdam hadden de vriendelijkheid alle geschriften van mej. Post, die zij bezaten, tot mijne beschikking te stellen, waarvoor ik hier nogmaals mijn dank betuig, maar daaronder bevond zich, ongelukkig, juist dit geschriftje niet. Wie wil het mij alsnog leenen?

Ik meen te mogen aannemen dat de plantage van den broeder in Demerary heeft gelegen. De namen der in het verhaal genoemde plantages - L'Heureuse Solitude, La bonne Espérance, La Bienveillance, La Récompense - vertoonen overigens groote overeenkomst met die van Surinaamsche plantages uit die dagen, veelal stichtingen van Fransche refugiés. Daar de mogelijkheid niet was uitgesloten dat de broeder eerst in Suriname ${ }^{\mathbf{1}}$ ), en later in Demerary het plantersbedrijf heeft uitgeoefend, heb ik in de „Surinaamsche Staatkundige Almanach", door Charles Brouwn uitgegeven en die voor de jaren 1793 tot 1796 verschenen zijn, de lijsten der plantages nageplozen, waarin, achter de plantagenamen, die der eigenaren, administra-

\footnotetext{
1) De moeder van de schrijfster was eene van Romondt, een naam in Suriname en op de Nederlandsch West-Indische Eilanden wel bekend.
} 
teurs en directeurs opgegeven zijn, maar de naam Post komt daarin niet voor. Voor zooveel ik weet bestaan zulke jaarboeken uit dien tijd voor de overige koloniën in Guiana niet.

Ik zeide reeds dat in het boek nergens een jaartal wordt genoemd. Een tijdsaanwijzing vind ik in het volgende: in het zesde boek (derde deel, blz. 209 vlg.) schrijft Reinhart, dat hij in „drie lange jaren”, wegens den oorlog, geen brief heeft kunnen verzenden of ontvangen. „Hoe levendig kan ik mij — schrijft hij — nog den naaren schrik, die op de eerste tijding, dat een naburige Zee-Mogendheid den oorlog aan mijn Vaderland verklaard, en den weg tot onderlinge gedachten-wisseling afgesneden had, mijn geheele ziel overmeesterde, herinneren!' ....

Die niet met name genoemde ,naburige Zee-Mogendheid" was Engeland, die op 19 December 1780 aan de Republiek den oorlog verklaarde. In het begin van 1781 maakten de Engelschen zich van Demerary, Essequebo en Berbice meester. Een jaar later - 17 Februari 1782 veroverde een Fransch eskader, onder bevel van den admiraal Graaf de Kersaint deze koloniën op de Engelschen. Bij den vrede van Parijs in 1783 werden de koloniën aan de vorige eigenaars teruggegeven. In Maart 1784 gingen de Franschen heen. Ziedaar de drie lange jaren waarover Reinhart schreef. In dien oorlog is Suriname, hoewel dikwijls bedreigd en meermalen door kapers van verbinding met Nederland afgesneden, door de Engelschen niet veroverd. Hier is dus ook een aanwijzing, van het land vanwaar de brieven van Reinhart kwamen. Zij wordt versterkt door de volgende woorden op blz. 213: „Behalve de voortbrengselen, welke ik intusschen na de landen van onze nieuwe beheerschers wegzond".... In dien oorlog heeft Suriname geen „nieuwe beheerschers” gehad. Bedoeld moet dus zijn Demerary, waar de broeder in 1809 is overleden. Daar hij vóór 1780 reeds geruimen tijd daar was, is zijn verblijf van zeer langen duur geweest. In Suriname is hij waarschijnlijk niet geweest.

Op volkenkundig gebied biedt het boek niet veel be- 
langrijks. Over de Indianen oordeelt Reinhart welwillender dan de meeste schrijvers uit die dagen:

„Welk een groot deel - schrijft hij in deel II, blz. 128 - van het menschdom maaken deeze en andere wilde natiën uit! hoe klein is het beschaafde deel der wereld, gerekend bij dat! en vergelijken wij dan deeze volken met elkander, zien wij de ondeugden die onder de besten heerschen, die edele zielen over het verval der menschlijke natuur doen bloozen, zou men dan niet de boosheid der duivelen bij deeze Wilden wachten? maar welke eene beschamende ervaaring! hier woonen nog deugden, schoon in eene ruwe gedaante, die beschaafder werelddeelen reeds ontvlugt zijn! wat zouden dan misschien deeze volken geworden zijn, zoo het schoone licht, dat in die oorden zoo glansrijk schittert, tot hen doorgedrongen ware, en de dikke nevelen in hunne ziel verstrooid hadde! welk een groot, edelmoedig, zedig volk waren dan welligt deeze verachte Bokken geworden!"

En op blz. 164:

....,,met een goeden indruk van hun karakter, zocht ik bij hen naar menschen-deugden, die mijne broederliefde wekken zouden: zooveel ik hunne taal magtig was sprak ik met hun, ondervroeg hun over veele dingen, en merkte uit hunne woorden, even als uit hun gelaat, onnadenkende trouw, loome goedheid, onverschillige onnozelheid, liefde tot rechtvaardigheid en rust"....

Voor den ethnoloog zijn de vrij uitvoerige mededeelingen over de Indianen evenwel niet van veel belang.

Merkwaardig is de beschrijving in deel II, blz. 240/241 van de begrafenis van een neger zijner plantage:

...., „Toen het zwarte lijk van den ontzielden Neger in een kist van ruwe planken - een zoo zachte slaapplaats als de meeste deezer arme wezens in hun leven te beurt valt - was neergelegd, dansten en sprongen zijne makkers, ook die van de naburige plantages, om hetzelve heen, en, als vergeetende dat zij eene wooning des doods omringden, beschouwden zij den ontzielden slaaf als een gelukkig reiziger naar het land der vrijheid, en veel gelukkiger dan zij; gaven hem op zijne reis bananes enz. tot teerkost, en kraalen tot sieraad, wanneer hij zou aankomen, mede; sommigen bevalen hem een reeks van groeten aan hunne vrienden en bekenden, wanneer hij in dat vrije land dezelven zou wederzien, even of dit verdervend stof hunne taal nog verstond, en nog eenige behoeften daaraan overbleeven; dan juichten en sprongen zij weder, even of 
zij vrolijk waren dat één hunner alrede over zijn lot zegepraalde, en dat zij hem eens zouden volgen"....

Bij de negerbevolking van Suriname komen deze gebruiken niet meer voor. Wèl bij de nog heidensche Boschnegers ${ }^{1}$ ).

Vóór ik afscheid neem van mejuffrouw Post's boek nog enkele opmerkingen:

„Reinhart behoort tot de eenzamen”, schrijft Koopmans. Dat blijkt uit het geheele boek, maar inzonderheid uit de brieven in den aanvang van het tweede deel, geschreven in den eersten tijd op zijn plantage „L'Heureuse Solitude". Hij vermijdt den omgang met de planters in de buurt, en dezen, wetende dat hun gezelschap hem niet welkom is, dringen hem dat niet op. Het gehalte van vele plantage-eigenaren en -directeuren liet in die dagen, en nog lang daarna, veel te wenschen over ${ }^{2}$ ), maar dat er uitzonderingen waren bewezen zijns vaders vriend Edelhart, die hem de plantage had geschonken en niet minder de brave man, die zijn schoonvader is geworden.

Hoe de planters op de plantages hun Zondagen doorbrachten beschrijft hij in de volgende woorden:

„De moegesloofde, de vadzige planter, zoo wel als zijne blanke bedienden, die zig zes dagen, in bezigheid en zorgen zagen ingewikkeld, verlangen naar deezen dag als een dag van rust en uit-

1) Het te Paramaribo verschijnende blad „De West” schrijft in zijn nummer van 15 Juni 1923 (correspondentie van Koffiekamp):

„De Boschnegerkapitein Amadé (van Koffiekamp aan de Sarakreek) van den stam der Aucaners, is Donderdag 7 Juni overleden, en is tot nu toe (12 Juni) niet begraven. Nacht aan nacht wordt in het sterfhuis door familie en vrienden gedanst en gezongen, de gewone gebruiken bij dergelijke plechtigheden. Men moet echter het orgaan van Boschnegers hebben om zulk een lijkenlucht vroolijk te blijven inademen. De kuil voor Amadé wordt op Sabakoekondre aan de Sarakreek gegraven. Dit werk ondervond echter oponthoud, omdat er geen dram was. Dit onmisbaar artikel moet gehaald worden van een plaatsje dagen van hier verwijderd. Het is te hopen dat het van daag komt, opdat van middag de begrafenis plaats vinde.

Intusschen is er gisteren een twaalfjarig jongetje gestorven op Redidotti, genaamd Basépai. Van diens overlijden zal echter niet veel „,werk” kunnen worden gemaakt, daar de dansers en danseressen nog afgemat zijn van het gepraesteerde bij den dood van Amadé."

2) Zie de „Encyclopaedie van Nederlandsch West-Indië”, blz. 639. In Demerary is het zeker niet anders geweest. 
spanning. en brengen die, ten deele in hunne hangmatten liggende, of zittende, in eene logge rust; ten deele in gezellige vrolijkheid, bij wijn, spel en dans door, terwijl zij, onvatbaar voor fijner en edeler vermaaken, hierin hunne grootste verademing vinden".

Reinhart had volkomen gelijk zijn Zondagen anders te willen doorbrengen, maar niet van de beste zijde doet hij zich kennen, wanneer hij een bladzijde verder uitroept:

„Doch is het niet akelig, mijn vriend! dat in deeze geheele Colonie geen schaduw van godsdienst te vinden is, bij menschen wier land God zegent, wier gewassen Hij doet groejen, wier goederen $\mathrm{Hij}$ in het dobberend schip den Oceaan overvoert, die Hij voedsel geeft, en in duizenden van gevaaren behoedt? Hoe dikwijls, wanneer ik mij voorstel, dat ik, in den omtrek van verscheidene mijlen, welligt de eenigste ben, die God hier hulde doet - hoe dikwijls weent mijne ziel dan over de diepte waarin de van God begunstigde mensch is neergestort, en die Hem, zoo ongelukkig voor zig zelven, als verachtelijk voor zijnen Weldoener worden doet."

Van denzelfden eigenwaan - of hoe het anders te noemen? - getuigt het, wanneer hij in een lateren brief 2e deel, blz. 210 - na een mooie natuurbeschrijving, deze verzuchting slaakt:

...., ,dan mijn vriend! wanneer de lieve Natuur mij door de streelendste gewaarwordingen verkwikt, en ik daarbij denk dat ik op deeze geheele Colonie welligt haar eenige priester ben; dat niemand hier - zoo hij al haare schoonheid gevoelde - haare gaven aan den Schepper wijdt", enz.

En ten slotte nog dit: het schrijven van een deel der brieven - en brieven van zulken omvang — op ,het vlies hetwelk de buitenschaal der [cocos]-vrucht bekleedt" tweede deel, blz. 107) en op een in de zon gedroogd vlies uit den stam van den "Oulcmary-boom" (tweede deel, blz. 107 en 141) neem ik op gezag van Reinhart aan, maar niet zonder daarbij een vraagteeken te plaatsen.

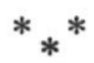

Het boek van Heinrich Stilling, meer bekend als JungStilling ${ }^{1}$ ) is een tweede stuk wild, dat door de samenstel-

1) Die Geschichte Florentins v. Fahlendorn. Drei Theile. Mannheim, in der neuen Hof- und akademischen Buchhundlang, 1781—83. 
lers van bovengenoemde Encyclopaedie niet is geschoten. Bij gelegenheid eener correspondentie met den heer $\mathrm{H}$. W. Heuvel, hoofd eener school te Borculo, over het boek van mej. Post vroeg hij mij of het boek van Stilling, dat voor een deel in Suriname handelt, mij bekend was. Hij bezat daarvan een Nederlandsche vertaling. Ik moest op de vraag ontkennend antwoorden. In de Koninklijke Bibliotheek alhier vond ik de Duitsche uitgave van $1781-83$, vermoedelijk de eerste. Brockhaus' Konversations-Lexikon (14e uitgave) vermeldt een tweede uitgave van 1825 en uitgaven van de gezamenlijke werken te Stuttgart van $1835-39$ in 14 deelen, en van $1841-42$ en 1843 - 44 in 12 deelen. Niettemin is „Die Geschichte Florentins v. Fahlendorn" een vrij zeldzaam boek. Na veel zoeken gelukte het mij een exemplaar machtig te worden, in Frankfort en Leipzig uitgegeven, zonder jaartal en zonder uitgeversnaam, ook in drie deelen, van iets grooter formaat dan de uitgave van $1781-83$. De Hollandsche vertaling, Arnhem 1790, is eveneens in drie deelen.

Stilling, die eerst het kleermakersvak leerde, ging later in de medicijnen studeeren te Straatsburg, waar hij omgang had met Goethe, die over hem schrijft in het $2 \mathrm{e}$ deel van "Aus meinem Leben".

Het verhaal is te verwikkeld om er een kort overzicht van te kunnen geven. Het behandelt de geschiedenis, bijna van hun geboorte af, van een braven jongen man, Florentin, en een brave jonge dochter, Rosine. Florentin was als kind door een brave boerenfamilie als zoon aangenomen en groeide met Rosine op. Onder machtige bescherming gaat het de jonge menschen voor den wind, tot er plotseling een keer komt in den gang van zaken. Florentin wordt op aanstichting van een paar deugnieten, de gebroeders Hallenborn, die het op Rosine gemunt hebben, door Hollandsche soldaten geprest, naar Amsterdam gevoerd, daar op een schip gebracht en naar Suriname gezonden. De oudste der twee broeders Hallenborn had in een duel een kameraad gedood, was als soldaat in Hollandschen zeedienst getreden, had in Suriname tegen de „wilden" gevochten, was daar tot luitenant bevorderd en 
daarna naar Duitschland teruggekeerd. Florentin's verwanten en beschermers reizen hem na naar Amsterdam, slagen er in hem op te sporen, maar alle pogingen om hem los te koopen mislukten. Op de reederij deelde men hun mede dat hij „vielerlei Unfug” bedreven had, „und seine Familie nicht gern Schimpf an ihn erleben mochte". Onder geen voorwendsel mocht hij worden losgelaten.

Men zou vragen: was er in die dagen geen politie en justitie te Amsterdam?

Het bedrog - zooals later bleek, een brief van Hallenborn met een valschen naam onderteekend - kwam uit toen het schip reeds vertrokken en niet meer te achterhalen was.

$\mathrm{Nu}$ wordt het verhaal gecompliceerd: Rosine wordt eveneens ontvoerd, maar uit de handen van haar ontvoerders gered door een braaf man - er komen in het boek vele voortreffelijke mannen voor - die haar negen maanden op zijn burcht houdt, al dien tijd trachtende haar te bewegen zijn vrouw te worden, wat zij volstandig weigert, niet zonder strijd getrouw blijvende aan haren verloofde, Florentin v. Fahlendorn.

Inmiddels zijn de beide Hallenborns met nog een zonderling heerschap, een zekeren Molkenblick, ook naar Suriname vertrokken.

Het tweede deel vangt aan met brieven van Florentin uit Suriname. Door bemiddeling van den kapitein van het schip, wordt hij geplaatst bij een Duitscher, Herr Pilger, die twintig mijlen landwaarts in, aan de Marowijne, een groote suiker- en koffieplantage bezat, Pilgersheim ${ }^{\mathbf{1}}$ ) genaamd, een onderneming die deze merkwaardigheid vertoonde, dat er geen slaven waren, „wohl aber Knechte und Mägde auf die Art, wie er in Europa üblich ist". Pilgersheim is een soort communistische gemeenschap. „Ich kann sagen - schrijft Florentin - dasz es vielleicht in der ganzen Welt keinen so vergnügten, angenehmen, und durchgehends wohlhabendern Ort, als Pilgersheim,

1) Zou de naam geïnspireerd zijn door Pilgerhut, den in 1740 door de Moravische Broeders in Berbice gestichten zendingspost? ( $\mathrm{Zie}$ „De WestIndische Gids", $2 \mathrm{e}$ jg. blz. 110). 
giebt”. Van Pilgersheim „bis Surinam” varen schepen, die aan de plantage behooren, en alle voortbrengselen naar de magazijnen der „Holländischen Compagnie” vervoeren en alle benoodigde Europeesche waren naar Pilgersheim.

Op meer dan een plaats in het verhaal ${ }^{\mathbf{1}}$ ) verzekert Stilling dat hetgeen hij schrijft waarheid is. Voor zooveel de terreinbeschrijving aangaat moet ik daarbij een groot vraagteeken plaatsen. Pilgersheim ligt aan de Marowijne, twintig mijlen landwaarts in, en daar ziet Florentin rotsen, die steeds hooger en wilder worden „so dasz sie in einer Entfernung von etlichen Meilen fast an die Wolken ragen". Maar hierbij blijft het niet. Op zekeren dag maken Florentin en Muzelius, de dominee van Pilgersheim, een tocht, niet ver van hun woonplaats. $\mathrm{Zij}$ beklimmen hooge, steile rotswanden, kruipen door nauwe spleten, zien bergmeeren die uitloopen in watervallen en komen na ongeloofelijke inspanning in een geheimzinnige Duitsche kolonie, van welker bestaan niemand iets wist, ook niet „die Holländische Regierung zu Surinam” en zelfs niet de Caraïben, die aan de rivier woonden, wien het anders niet aan speurzin ontbreekt.

„Welch wonnevolles Entsetzen durchdrang uns, als wir uns umsahen! - Gegen Morgen hin fiel uns ein Lustgefilde in die Augen, das alles übertrift, was ich je gesehen habe: es war länglicht-rund, von Westen gegen Osten bei anderthalb Stunden lang, von Norden gegen Süden drei Viertelstunde breit, und allenthalben mit einem schrofen und zackigten Felsengebirge umgeben. Gegen Osten aber thürmten sich die Felsen hintereinander in die Höhe bis an die Wolken, und die obersten Spitzen waren lauter Schnee und Eis"....

Dit alles zegt Florentin; maar nu een andere aanhaling waar Stilling zelf aan het woord is:

„Ich kann sagen, es schmerzt mich allemal in der Seele, wenn ich sitze und so Geschichte male, und man fordert von mir, dasz ich jedes Blättgen an den Baümen, jedes Fältgen im Gewande, so ganz rein heraus zirkeln soll, ich wünschte so mit einem Pinselzuge ganze Wasserfälle und Felsengruppen, und Baüme hinklecksen

1) Zoo b.v. op blz. 51, 52, 53 en 145 van het derde deel. 
zu können, aber das will mir noch nicht recht gelingen; gut! dasz ich kein Romanendichter von Profeszion bin".

Wat de „Wasserfälle und Felsengruppen” betreft is hem het „hinklecksen” wonderwel gelungen.

Het hoofd der kolonie was een grijsaard, Christian Gotlieb Pracht, afkomstig uit Saksen, die in zijn jonge jaren met een jonge gravin er van door gegaan was. De plaats heette Solyma en elke afzonderlijke woning had een bijbelschen naam. Mannen en vrouwen gingen geheel in het wit gekleed. Allen waren nakomelingen van Herr Pracht. Men was in Solyma volkomen op de hoogte van ,,alle Verfassungen von Surinam, Pilgersheim und andern Holländischen Kolonien”, maar, verklaarde Pracht, „Wir haben keinen gröszeren Zweck bei unserer Wirthschaft, als uns nach und nach von der ganzen Welt unabhängig zu machen, so, dasz wir selbst in Solyma alles erziehen, und machen können was zu unserer Bequemlichkeit gehört".

Hoe de kolonisten kwamen aan de levens-benoodigdheden, buiten hetgeen zij zelven konden maken, wordt zeer geheimzinnig verteld. Zij bezaten verscheidene kudden runderen, die het Friesche en Zwitsersche vee overtroffen. $\mathrm{Zij}$ verbouwden katoen en vlas en het kostte hun weinig moeite den grond te bebouwen, want het was daar eeuwige lente. Goud werd er gegraven voor hun geheimen handel met Pilgersheim en de overige kolonie Suriname.

Bij een tweede bezoek aan Solyma vonden Florentin en Muzelius daar den jongsten Hallenborn en Molkenblick .... in de gevangenis. Deze waren ook tot den heilstaat doorgedrongen en dadelijk begonnen met de jonge mannen en meisjes het hoofd op hol te brengen. Herr Pracht greep krachtig in en liet de beide kornuiten opsluiten. In de gevangenis moesten zij bijbels overschrijven en Prachts' catechismus. Men had n.l. gebrek aan gedrukte exemplaren. Schreven ze niet ijverig en accuraat dan kregen zij geen eten. Hallenborn stierf in de gevangenis, maar Molkenblick hield het uit en werd later een lid van de kolonie. De oudste Hallenborn, die officier in Surinaamschen dienst was, pleegde verraad. Hij wilde n.l. een aanval der 
Franschen op Pilgersheim in de hand werken. Het complot werd ontdekt en de verrader onthoofd en gevierendeeld! Men deed het toen niet minder.

Niet lang hield de kolonie van Pracht stand. Na zijn dood kwam er verdeeldheid. Solyma was nu algemeen bekend geworden. Een deel der kolonie sloot zich bij Pilgersheim aan, het andere deel bleef onder Pracht's zoon „doch unter der Regierung zu Surinam”.

Ik kan de verzoeking niet weerstaan den lezer hier een enkel proefje te geven van Florentin's kijk op de Caraïben:

„Ja, es ist wahr, der Löw ist majestätisch gebildet, und er siehet fürchterlich schön aus; aber das alles ist Kinderspiel gegen einen Caraiben. Welch eine Kreatur ist doch der Mensch im Stande der wilden Natur! - was muszte Adam seyn? - Wir haben in Europa Fürsten, die majestätisch aussehen; aber das ist nichts gegen einem wohlgebildeten Wilden"....

Geen wonder dat, bij het zien van deze mannen, hem, „gleichsam das Herz im Leibe erstarb”, hem „ein kalter Schauer über die Haut ging”, en hij dacht: „Gott! welche Milchsuppen- und Alltagsgesichter haben wir Europäer!....

In Pilger had Florentin een goeden vriend en machtigen beschermer gevonden. Na een paar jaren vertrekt hij met een zekeren heer Peter von Fink, een vriend van Pilger, een soort deux ex machina in het verhaal, braaf man, maar onverbeterlijk raisonneur, over Noord-Amerika naar Duitschland. Daar vindt hij Pilger, die inmiddels Suriname ook had verlaten, Pilgersheim latende aan $\mathrm{Mu}-$ zelius, die inmiddels getrouwd was met een Caraïbische schoone, Zarima, de dochter van den Kazike. Op het eerste gezicht had zij Muzelius tot man begeerd. Tot niet geringe verbazing van Florentin ontpopte Pilger zich als Graaf Günther van Eichenborn, de broeder van den regeerenden graaf, die zijn onderhoorigen zeerslecht behandelde. Graaf Günther was in onmin met zijn broeder geraakt, was naar Amsterdam uitgeweken, met een Hollandsche vrouw getrouwd en naar Suriname vertrokken, 
waar hij Pilgersheim stichtte. Zijn einde voelende naderen kreeg de broeder berouw over zijn daden en wilde zich met Günther verzoenen. Deze kreeg daarvan door zijn vriend von Fink bericht, kwam terug, werd de regeerende graaf en Florentin zijn ,geheimer Rath”.

Jung Stilling heeft heel wat van zijn landgenooten, van zeer diverse pluimage, naar Suriname weten over te planten. Met de goeden is het voor den wind gegaan, de deugnieten hebben er hun gerechte straf gevonden, alles zooals het behoort in een echten roman.

Van de personen in het verhaal, die thuis zijn gebleven, heb ik hier niet gesproken. Zij zijn over het algemeen aardig geteekend, met voorliefde Rosine. De aantrekkelijkste figuur is, hoewel hij weinig naar voren treedt, m. i. de boer Lorenz, de pleegvader van Florentin.

Het verhaal eindigt met een algemeene trouwerij; in het geheel telde ik vier paren.

Die den gemoedelijk vertelden roman begint te lezen zal dien zeker met veel genoegen verder lezen.

Ten slotte deze vraag: Hoe kwam Stilling, die toch niet de eerste de beste was, tot zoo'n wonderlijke topografie van de Beneden-Marowijne? De communistische koloniën Pilgersheim en Solyma zou men op den koop toenemen als hij niet zoo uitdrukkelijk had verzekerd dat wat hij schreef waarheid was.

Den Haag, December 1924.

H. D. B. 